\title{
Áairman
}

Jurnal Teknik dan Keselamatan Transportasi

\section{Rancang bangun Kontrol dan Monitoring pada Prototype Emergency Solar Runway Edge Light}

\section{Design of Control dan Monitoring Prototype of Emergency Solar Runway Edge Light}

\author{
Castro Van Bronson', Taryana $^{2}$ \\ castrobronsonaee19@gmail.com, ppi@ppicurug.ac.id
}

Politeknik Penerbangan Indonesia Curug

\begin{abstract}
ABSTRAK
Kebutuhan sistem Remote Kontrol semakin meningkat, memudahkan manusia untuk dapat mengoptimalkan kinerja pada pekerjaan setiap waktu. Tujuan penelitian ini adalah merancang sistem kontrol lampu seperti pada kasus runway di salah satu bandara Indonesia yang terjadi short pada kedua sircuitnya. akibatnya sejumlah penerbangan bandara itu dialihkan ke bandara yang lainnya, biasanya kita menggunakan lampu emergency darurat. Penelitian ini bertujuan untuk mengontrol lampu prototype emergency solar runway edge light dengan menggunakan alat komunikasi jarak jauh radio freuensi dengan dua arah. Mikrokontroler Arduino Nano 328 dimanfaatkan sebagai alat untuk memproses data dari sistem yang berfungsi untuk mengirim perintah ke modul client dan mengirim data sensor arus dan tegangan ke modul console untuk ditampilkan di sistem monitoring. Metodologi yang digunakan adalah metode Pustaka, Observasi serta rancangan alat, Bahasa Pemograman yang digunakan adalah bahasa $C$. dengan sistem ini mempermudah untuk pengoperasian lampu yang lebih praktis.
\end{abstract}

Kata kunci: Remote Kontrol; Sistem Monitoring; Mikrokontroler Arduino Nano 328; Prototype Emergency Solar Runway Edge Light

\section{ABSTRACT}

The need for remote control systems is increasing, making it easier for humans to be able to optimize performance on the job at any time. The purpose of this study is to design a light control system as in the case of the runway at one of Indonesia's airports that occurred short on both circuits. As a result, a number of airport flights were diverted to other airports, usually, we use emergency lights. This research aims to control the prototype emergency solar runway edge light by using a long-distance radio frequency communication tool in two directions. Arduino Nano 328 microcontroller is used as a tool to process data from the system that serves to send commands to the client module and send current and voltage sensor data to the console module to be displayed in the monitoring system. The methodology used is the method of Literature, Observation, and tool design, the Programming language used is $C$. with this system makes it easier for more practical operation of lights.

Keywords: Remote Control; Monitoring System; Arduino Nano 328 Microcontroller; Prototype Emergency Solar Runway Edge Light 


\section{PENDAHULUAN}

Perkembangan dalam dunia teknologi menyebabkan peningkatan kebututuhan alat untuk membantu manusia, diantaranya kebutuhan sistem remote kontrol yang dapat memudahkan manusia untuk dapat mengoptimalkan kinerja pada pekerjaan disetiap waktu.

Kemajuan teknologi di bidang elektronika dan instrumentasi yang memasuki segala bidang kehidupan, diantaranya pada teknologi pengoperasian jarak jauh dan sistem monitoring.

Seperti yang disebutkan dalam Aerodrome Design Manual Part 5 Electrical System bagian separation of lighting facilities menyebutkan bahwa adanya CCR standby tetapi saat ini kondisi di bandar udara tersebut belum memiliki fasilitas CCR spare. Karena hal tersebut ada sembilan penerbangan pada malam itu ditunda dan pesawat yang akan mendarat di Batam dialihkan ke Bandara Pekanbaru. Kemudian setelah kejadian tersebut pihak bandar udara meminta kepada Kementerian Perhubungan agar menggunakan alat bantu penerangan runway portabel dengan tujuan meminimalisir dampak kerugian penerbangan di Bandara Hang Nadim Batam.di sisi udara dimana jangkauanya sangat luas, nantinya pengoperasiannya pada alat ini mencapai $\pm 2 \mathrm{KM}$ dan di dalamnya terdapat komponen potensimeter slider yang dapat mengatur tingkat kecerahan lampu. [ANEX, ICAO, 2016]

Kemudian untuk sistem monitoringnya sendiri menggunakan LCD character yang dapat menampilkan status pengoperasian pada lampu, seperti indikator tegangan dan arus pada prototype tersebut. Yang nantinya rancangan ini berbentuk portable agar memudahkan para teknisi memonitoring pengoperasian, salah satu peralatan visual aids ketika dalam keadaan emergency.

\section{METODE}

Tahap ini, penulis menggunakan alat bantu pendukung teori, buku - buku Pustaka, sumber dari internet dan jurnal, refrensi - refrensi atau sumber lain yang berkaitan dengan sistem kontrol lampu menggunakan remote kontrol dan

tambahan sistem monitoring. Berdasarkan hasil studi literatur penulis mendapatkan materi - materi yang akan digunakan untuk penelitian ini, yaitu cara - cara merancang alat dan komponen - komponen yang harus digunakan dalam merangkai alat, Hal ini dilakukan untuk memberikan gambaran umum secara tidak langsung dari

perencanan. Selain dari konsep perencanaan yang akan dibuat, bagian ini akan membahas mengenai waktu dan lokasi perencanaan, Desain Perencanaan serta cara kerja Perancangan ini.

\section{Metode Pengumpulan Data}

1. Desain Perancangan

Perlu diketahui pada bagian ini penulis akan menjelaskan konsep dari rancangan yang akan dibuat. Berkaitan dengan hal ini, penulis menginginkan agar terdapat pengoperasian jarak jauh dan tambahan sistem monitoring pada lampu Prototype Emergency Solar Runway Edge Light memudahkan para teknisi untuk pengoperasiannya. Rancang bangun yang akan dibuat adalah kontrol dan monitoring dimana pengoperasiannya menggunakan radio frekuensi dengan tambahan sistem monitoring LCD character $2 \times 16$. [U. J. Shobrina, R. Primananda, And R. Maulana, 2018]

Berdasarkan kondisi yang akan dibuat pada lampu prototype masih dioperasikan secara manual

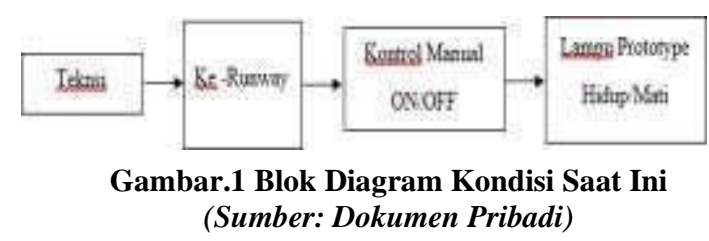


Berdasarkan kondisi tersebut, penulis menginginkan pengoperasian otomatis. Kondisi dengan adanya

rancangan ini adalah sebuah pengoperasian remote kontrol jarak jauh yang menggunakan radio frekuensi dengan tambahan sistem monitoring

LCD character, yang nantinya berbentuk portable. Perancangan sistem secara keseluruhan terdapat modul pemancar atau disebut modul console dan modul penerima disebut modul client.

Pada rancangan ini terdapat dua modul Arduino Nano 328 yang berfungsi sebagai otak dalam rancangan ini dengan memproses data dan mengirim data dan modul NRF24L01 sebagai alat komunikasi jarak jauh yang saling memancarkan radio frekuensi. Dalam rangkaian modul utama yaitu modul console terdapat modul switch toggle ON- OFF-ON dan modul potensiometer untuk mengatur tingkat kecerahan lampu kemudian ada Arduino Nano 328 dan LCD $2 \times 16$ sebagai penampil aksi kendali dengan adanya modul sensor, bersamaan dengan modul penerima, yang didalamnya terdapat

modul NRF24L01,Arduino Nano, modul sensor dan modul dimmer.

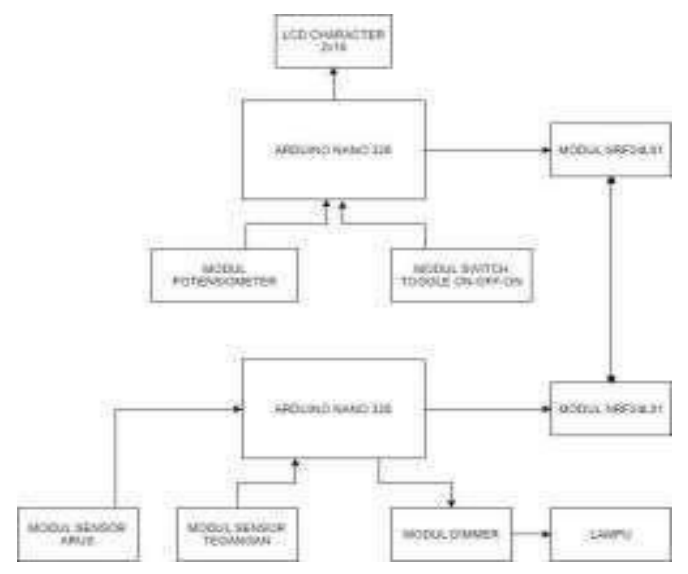

Gambar 2. Wiring komponen (Sumber: Dokumen Pribadi)

Pada proses penentuan alat dan bahan, membuat rancangan pengoperasian dengan alat komunikasi jarak jauh dan tambahan sistem monitoring, terdiri dari modul utama yang disebut modul console dan modul client yang didalamnya terdapat modulmodul dan komponen pendukung sebagai berikut:

a. Modul NRF24L01.

b. Modul Arduino Nano 328.

c. LCD (Liquid Crystal Display) $2 \times 16$.

d. Modul Voltage Sensor Module For Arduino.

e. Modul ACS712 Current Sensor 20 A.

f. Mosfet Power Switch DC 400W.

g. Holder Battery Kotak 9V.

h. Potensiometer Stereo 100K WH148.

i. Knop Cap Rotary Encorder Potensiometer.

j. Saklar Toggle MTS-203 Switch DPDT ON-OFF-ON.

$k$. PCB Lubang Prototype PCB Bolong $13 \times 25 \mathrm{~cm}$.

\section{Cara Kerja Perancangan}

Pada rancang bangun ini, memiliki beberapa tahapan pada cara kerja perancangan dimulai dari rancang bangun instrument lalu pemograman pada arduino nano 328 yang sudah disetting dari computer

ke Arduino kemudian dilanjutkan dengan perancangan elektronik skala kecil. Sebuah rancangan pengoperasian jarak jauhdengan dua arah yang menggunakan alat modul komunikasi jarak jauh disebut modul NRF24L01 yang ditempatkan pada kedua modul utamayaitu modul console dan modul client begitu juga untuk modul ArduinoNano 328 dikedua modul utama tersebut yang berfungsi sebagai pengolah data.

Dimulai dari sebuah modul console yang dipegang atau dikendalikan oleh operator untuk memberi perintah kepada modul client, yang dipasang pada lampu prototype emergency solar runway edge light dengan menjumper rangkaian saklar manual. Lalu proses inisialisasi dimana

mikrokontroler yang digunakan, memanggil library (mempersiapkan perintah-perintah saat menggunakan mikrokontroler Arduino), kemudian sensor arus dan tegangan pada modul client mendeteksi dan membaca status lampu protoype tersebut kemudian diterima oleh modul console, dan diolah oleh arduino nano 328 untuk dikirim ke LCD character $2 \times 16$ sebagai tampilan proses pengoperasian. Dan modul ini memberikan perintah switch toggle ON-OFF-ON dan ada juga modul potensiometer untuk mengatur tingkat 
kecerahan lampu yang dioperasikan oleh operator atau teknisi. nano 328 untuk dikirim ke LCD character $2 \times 16$ sebagai tampilan proses pengoperasian.
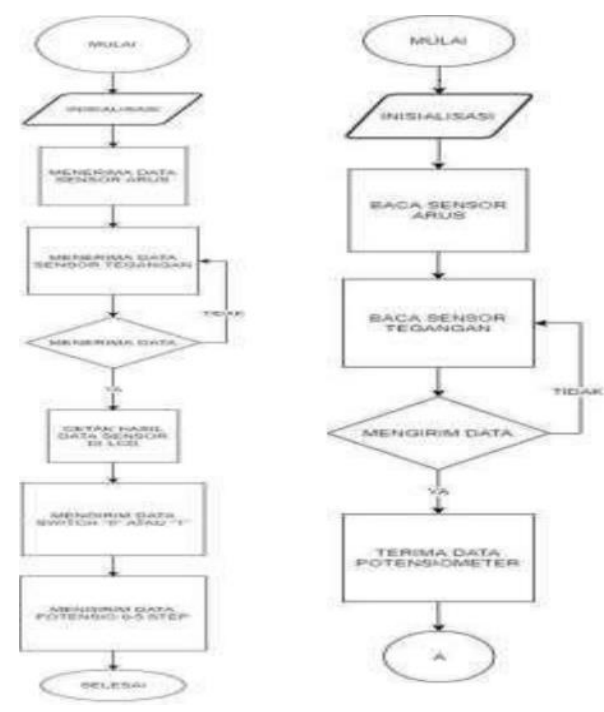

Gambar 3. Flowchart Modul Console

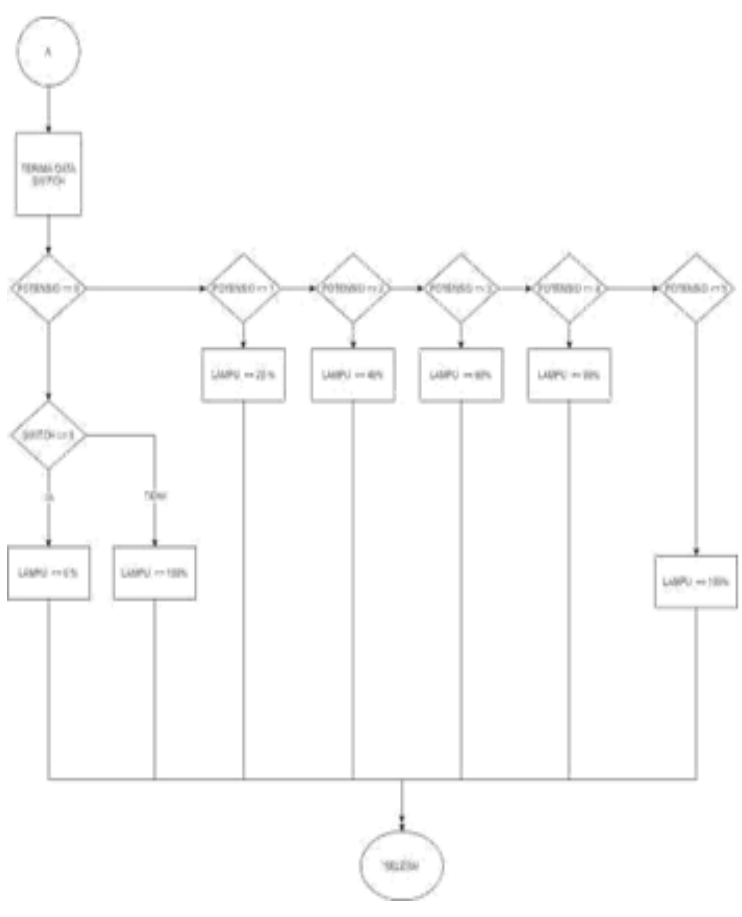

Gambar 4. Flowchart Modul Client pada Prototype Emergency Solar Runway Edge Light yang nantinya dipasangkan pada lampu prototype tersebut untuk pengoperasian jarak jauh. Dengan kondisi yang ada saat ini masih manual dalam pengoperasiannya, pada rancangan ini penulsi menggunakan perangkat keras (Hardware) dan juga perangkat lunak(Software) dimana proses pemograman mikrokontroler dilakukan pada software Arduino IDE dan untuk perangkat keras (Hardware) yang digunakan remote kontrol dua arah yang fisiknya berbentuk portable.

Komponen- komponen yang digunakan terdiri dari modul transmitter atau disebut modul console, LED character $2 \times 16$, modul receiver atau disebut modul client yang di dalamnya ada modul NRF24L01, yang berfungsi untuk komunikasi jarak jauh yang dipasang juga dirangkaian pada modul console kemudian modul switch ON-OFF-ON pengoperasian lampu dan modul potensiometer sebagai pengatur tingkat kecerahan lampu, lalu ada modul sensor arus, modul tegangan dan terakhir modul Arduino Nano 328 yang dipasang juga pada rangkaian modul console mengolah proses pengiriman data dan di modul client inputnya diperoleh dari hasil baca sensor arus dan tegangan dan output dari arduino nano 328.

\section{Tahapan Pembuatan Rancangan}

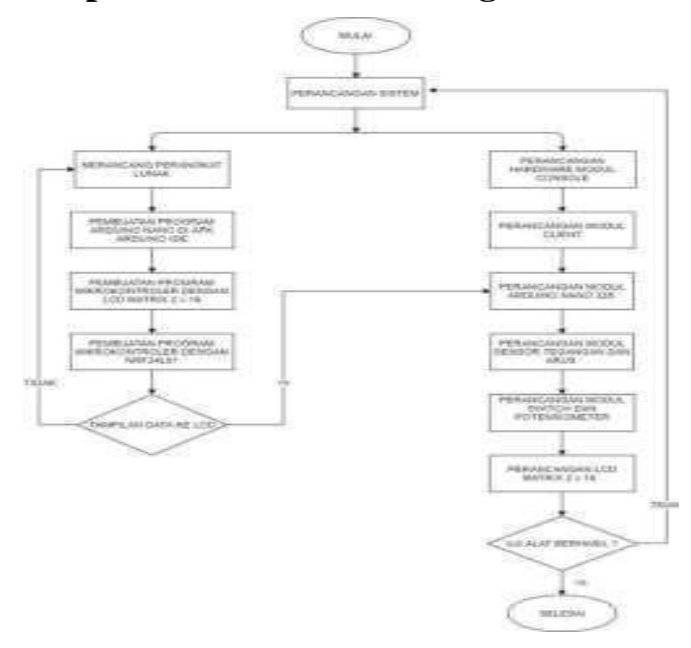

Gambar 5. Flowchart Tahapan Pembuatan Rancangan

\section{HASIL DAN PEMBAHASAN}

\section{Perangkat Keras (Hardware)}

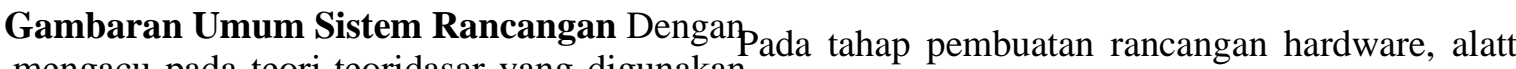

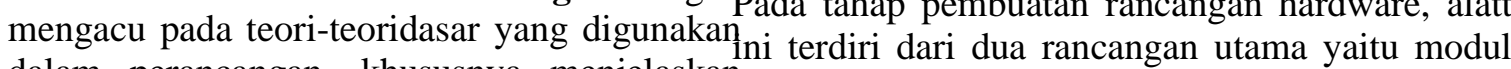
dalam perancangan, khususnya menjelaskan consoledan modul client yang didalamnya terdirii proses perancangan kontrol dan monitoring 
dari beberapa modul lagi.

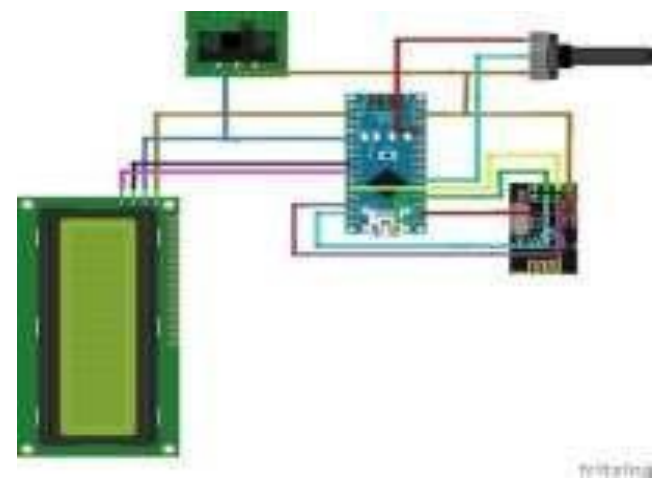

Gambar 6. Rancangan Modul Console

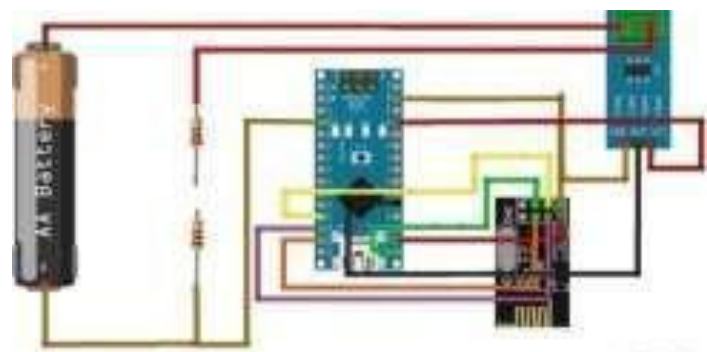

Gambar 7. Rancangan Modul Client

Pada tahapan ini penulis melakukuan beberapa pengujian pada beberapa modul yang ada pada modul utama yaitu modul console dan modul client. Adapaun beberapa modul yang ada pada modul utama yang ingin dilakukan pengujian

a. Baterai sebagai catu daya $9 \mathrm{~V}$

Pada rancangan alat yang dibuat ini membutuhkan baterai sebagai sumber catu daya mikrokontroler. Untuk console dan LCD character $2 \times 6$ tidak memerlukan catu daya sediri, melainkan mendapat catu daya dari mikrokontroler. Catu daya yang digunakan yaitu baterai yang keluarannya menghasilkan tegangan 9 VDC, tujuan dari pengujian ini adalah untuk mengetahui keluaran, sudah stabil atau belum.

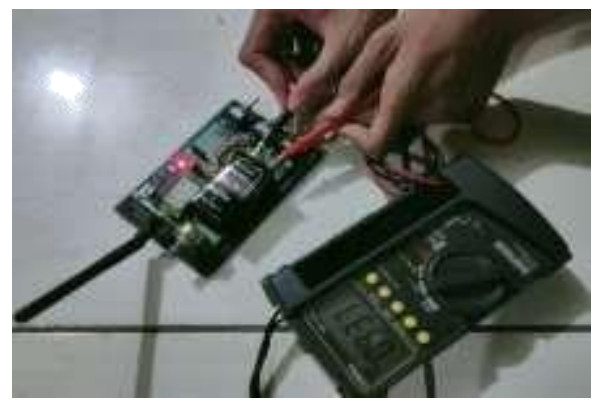

Gambar 8. Pengujian Catu Daya

Cara pengujian:

- Siapakan baterai yang akan diuji.
- Hubungkan baterai ke input mikrokontroler console.

- Ukur output dari mikrokontroler console menggunakan Avometer.

Hasil pengukuran pada catu daya ini bisa dilihat pada tabel dibawah ini:

Tabel 1 Hasil Pengujian Catu Daya

\begin{tabular}{|c|c|c|}
\hline Uji ke- & $\begin{array}{c}\text { Tegangan } \\
\text { Input }\end{array}$ & $\begin{array}{c}\text { Tegangan } \\
\text { Output }\end{array}$ \\
\hline 1 & 9 VDC & 9 VDC \\
\hline 2 & 9.1 VDC & 9 VDC \\
\hline 3 & 9 VDC & 9 VDC \\
\hline
\end{tabular}

Dari hasil pengujian, didapatkan kesimpulan bahwa baterai berada pada kondisi baik. Dari 3 percobaan yang telah dilakukan, keluaran baterai sebagai catu daya terbilang stabil.

\section{b. Arduino Nano 328}

Arduino Nano 328 dapat menghubungkan modul pengontrolan untuk pengoperasian dan sistem monitoring ke LCD character $2 \times 16$. Tujuan dari pengujian pada Arduino Nano 328 berfungsi untuk mengecek kesiapan kondisi modul mikrokontroler console dan mikrokontroler client.

Didalam arduino nano terdapat beberapa pin (masukan) dan port (keluaran).

Pada pin yang mendapat data yang dikirim dari modul console ke modul client dan data tersebut diolah untuk ditampilkan pada LED character 2 $\times 16$.

Tujuan dari pengujian pada arduino nano ini untuk mengecek kesiapan kondisi board arduino nano dalam menerima perintah

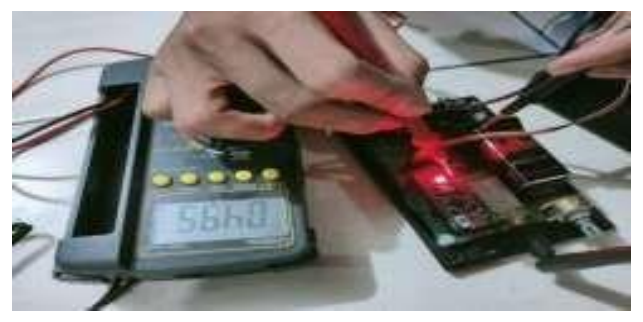

Gambar 9. Pengujian Arduino Nano 328 Pada Modul Console (Sumber: Dokmen Pribadi) 
Cara pengujian:

- Hubungkan Arduino Nano dengan power supply dengan menjalankan program kerja alat degan status ON.

- Lihat tampilan status pengoperasian lampu prototype pada LED.

- Tempelkan probe merah AVO meter pada pin Vcc dan probe hitam pada pin Ground.

- Cek tegangan yang mengalir.

Hasil pengujian arduino nano ini bisa dilihat pada tabel dibawah:

Tabel 2. Hasil Pengujian Arduino Nano 328 pada modul Console

\begin{tabular}{|c|c|c|}
\hline Uji ke- & $\begin{array}{c}\text { Tegangan } \\
\text { Input }\end{array}$ & $\begin{array}{c}\text { Tegangan } \\
\text { Output }\end{array}$ \\
\hline 1 & 9 VDC & 4.9 VDC \\
\hline 2 & 9 VDC & $5 \mathrm{VDC}$ \\
\hline 3 & $9 \mathrm{VDC}$ & $5 . \mathrm{VDC}$ \\
\hline
\end{tabular}

Dari hasil pengujian, didapatkan kesimpulan bahwa Arduino Nano 328 berfungsi dengan baik. Hal ini dibuktikan dengan tegangan yang mengalir pada arduino sebesar \pm 5 Vdc. Selain itu dilihat juga dari indikator monitoring yang menampilkan status pengoperasian di LCD $2 \times 16$ yang telah dihubungkan dengan arduino nano maka arduino nano masih berfungsi dengan baik.

Dari hasil pengujian, didapatkan kesimpulan bahwa Arduino Nano 328 berfungsi dengan baik. Hal ini dibuktikan dengan tegangan yang mengalir pada arduino sebesar \pm 5 Vdc. Selain itu dilihat juga dari indikator monitoring yang menampilkan status pengoperasian di LCD character $2 \times 16$ yang telah dihubungkan dengan arduino nano maka arduino nano masih berfungsi dengan baik

\section{c. Modul NRF24L01 Pada Console}

Sebuah modul komunikasi jarak jauh yang bekerja pada gelombang RF 2,4-2,5 GHz. Dalam rancangan ini dibuat remote pengoperasian jarak jauh dengan dua arah. Modul ini menggunakan Serial Peripheral Interface (SPI) untuk komunikasi Tegangan kerja dari modul ini adalah $5 \mathrm{Vdc}$. Konsumsi arus pada modul ini sangat rendah yaitu $9 \mathrm{~mA}$. Pin yang terdapat pada modul NRF24L01 adalah VCC, GND, CSN, CE, MOSI, MISO, IRQ.
Pin VCC atau pin power pada modul NRF24L01 yang berfungsi untuk input tegangan sebesar 3,3 V. Pin GND atau disebut pin ground pada modul berfungsi untuk menghubungkan modul ke ground pada sistem ini. Pin CE atau disebut pin Chip Enable pada modul berfungsi untuk mengaktifkan komunikasi SPI (Serial Peripheral Interface). Pin CSN atau disebut Chip Select Not pada modul berfungsi untuk mengaktifkan input high atau memastikan SPI pada keadaan selain High. Pin SCK atau disebut Serial Clock pada modul berfungsi untuk memasukan input clock pada komunikasi SPI.

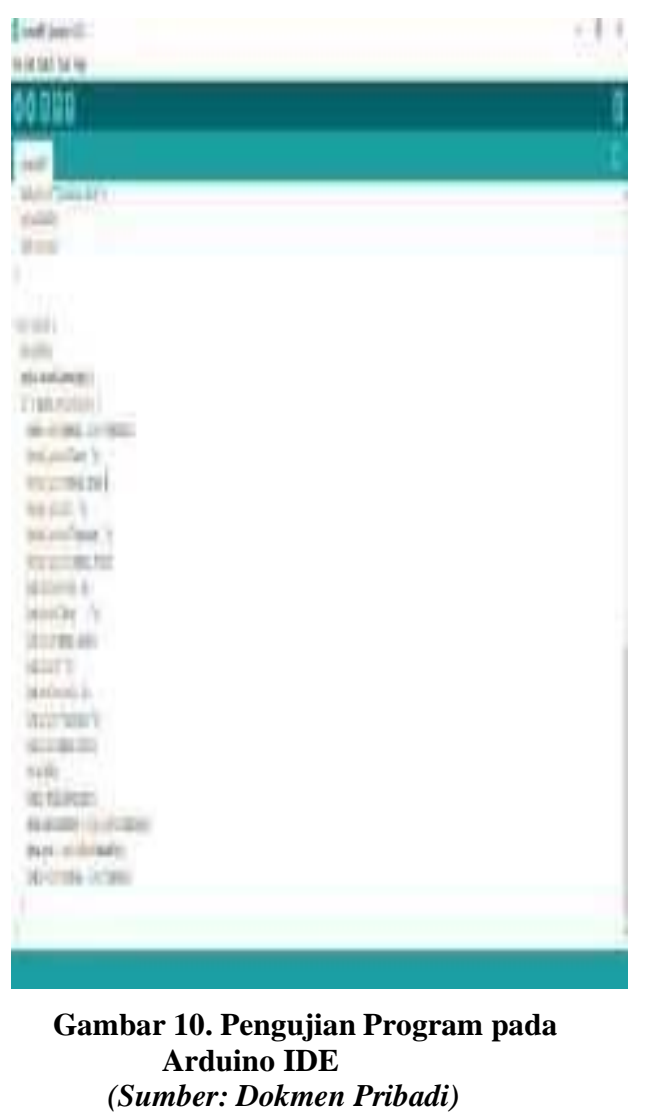

Tabel 3. Hasil Pengujian NRF24L01 pada Modul Console

\begin{tabular}{|c|c|c|}
\hline Uji ke- & $\begin{array}{c}\text { Tegangan } \\
\text { Input }\end{array}$ & $\begin{array}{c}\text { Output } \\
\text { NRF24L01 }\end{array}$ \\
\hline 1 & 3.4 VDC & BAIK \\
\hline 2 & 3.5 VDC & BAIK \\
\hline 3 & 3.4 VDC & BAIK \\
\hline
\end{tabular}


Cara pengujian:

- Hubungkan modul NRF24L01 ke Arduino Nano 328.

- Sambungkan Arduino Nano dengan PC.

- Buka Software Arduino IDE.

- Klik pada program untuk modul NRF24L01.

- Upload program ke board Arduino Nano 328.

- Klik icon Serial Monitor pada pojok kanan atas Arduino IDE.

- Kemudian Cek tegangan Input Pada Modul tersebut

- Tempelkan probe merah AVO meter pada pin Vcc dan probe hitam pada pin Ground.

\section{d. Modul NRF24L01 Pada Client}

Pada rancangan ini modul NRF24L01 digunakan untuk modul client. Tujuan dari pengujian ini untuk mengecek kesiapan modul NRF24L01 dalam kesiapan komunikasi jarak jauh dalam pengoperasian. [J. Shobrina. R, Primananda And R. Maulana, 2018]

Dari hasil pengujian, didapatkan kesimpulan bahwa NRF24L01 pada modul client berfungsi dengan baik. Hal ini dibuktikan dengan tegangan yang mengalir pada NRF24L01 3.5 Vdc.

\section{e. LCD Character $2 \times 16$}

LCD untuk memonitoring yang telah dirangkai sedemikian rupa, perlu dilakukan uji coba. Pada pengujian tampilan LCD Character $2 \times 16$ ini untuk memastikan pengolahan data yang diterima dan ditampilkan pada komponen tersebut sudah bekerja dengan baik.

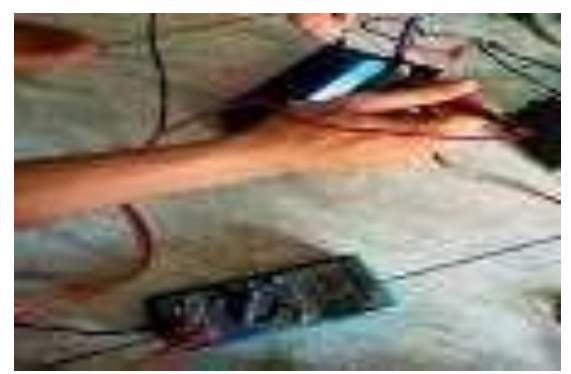

Gambar 11. Pengujian LCD Character2×16 (Sumber: Dokmen Pribadi)

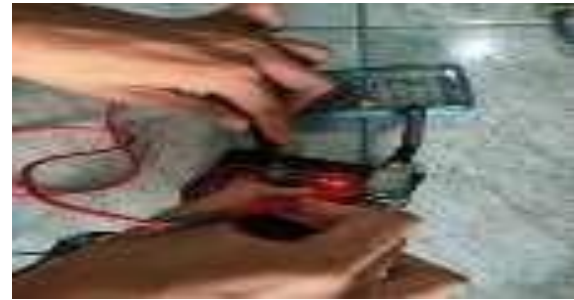

Gambar 12. Pengujian NRF24L01 pada Modul Client. (Sumber: Dokmen Pribadi)

Cara pengujian :

- Hubungkan NRF24L01 pada modul client dengan sudah tersambung catu daya.

- Tempelkan probe merah AVO meter pada pin $V c c$ dan probe hitam pada pin Ground.

- Cek tegangan yang mengalir

Tabel 5. Hasil Pengujian NRF24L01 pada Modul Client

\begin{tabular}{|c|c|c|}
\hline Uji ke- & Tegangan Input & Output \\
\hline 1 & $3.5 \mathrm{VDC}$ & BAIK \\
\hline 2 & $3.5 \mathrm{VDC}$ & BAIK \\
\hline 3 & $3.5 \mathrm{VDC}$ & BAIK \\
\hline
\end{tabular}

Cara pengujian:

- Hidupkan tombol ON pada switch toggle pada modul console dengan sudah tersambung catu daya.

- Tempelkan probe merah AVO meter pada pin $V c c$ dan probe hitam pada pin Ground.

- Cek tegangan yang mengalir.

Tabel 6. Hasil Pengujian LCD Character

\begin{tabular}{|c|c|c|}
\hline Uji ke- & $\begin{array}{c}\mathbf{2} \times \mathbf{1 6} \\
\text { Tegangan } \\
\text { Input }\end{array}$ & Output DMD \\
\hline 1 & $5 \mathrm{VDC}$ & MENYALA \\
\hline 2 & $4.9 \mathrm{VDC}$ & MENYALA \\
\hline
\end{tabular}

Dari hasil pengujian, didapatkan kesimpulan bahwa komponen tersebut dapat berfungsi dengan baik. Hal ini dibuktikandengan 2 kali percobaan yang menunjukan bahwa LCD character $2 \times 16$ dalam kondisi baik

\section{f. Modul Sensor Arus}

Modul sensor arus pada rancangan ini menggunkan sensor arus ACS712 sensor yang berfungsi membaca arus pada lampu prototype lalu diproses oleh arduino nano dan dikirim ke LCD character $2 \times 16$. Sensor arus terdiri dari 
dari rangkaian elektronik yang berfungsi mengubah arus menjadi tegangan listrik sensor arusyang digunakan dalam rancangan ini ACS712 $20 \mathrm{~A}$

Pada pengujian modul ini dilakukan untuk memastikan modul berfungsi agar dapatditampilan di modul LCD character $2 \times 16$ sudah bekerja dengan baik. Pada pengujian ini didapatkan data yang telah dibaca oleh sensortersebut sebagai berikut

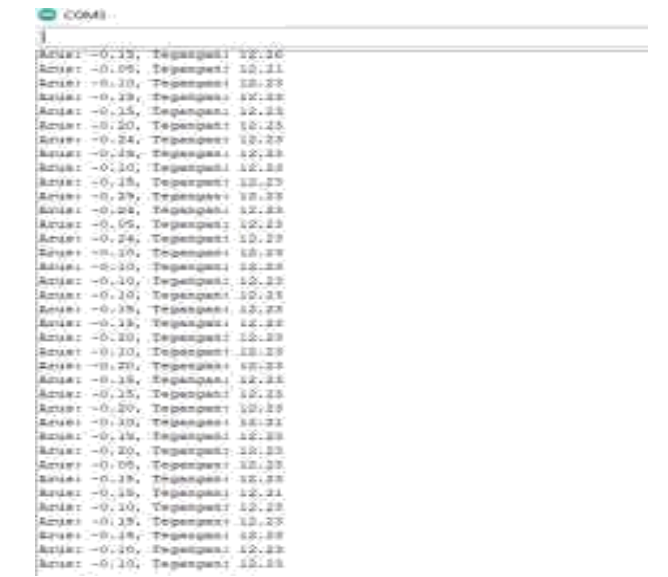

Gambar 13. Pengujian Modul Sensor Arus Dengan Hasil Data(Sumber: Dokmen Pribadi)

Cara pengujian:

- Hubungkan modul sensor arus dengan arduino nano 328.

- Hubungkan arduino nano 328 ke PC.

- Buka software Arduino IDE

- Klik pada program untuk modul sensor arus dan tegangan

- Upload program dari PC ke Arduino Nano 328.

Tabel 7. Hasil Pengujian Modul Sensor Arus

\begin{tabular}{|c|c|c|}
\hline Uji $\boldsymbol{k e}$ - & Input Arus & Output Arus \\
\hline 1 & $20 \mathrm{~A}$ & $20 \mathrm{~A}$ \\
\hline 2 & $20 \mathrm{~A}$ & $20.1 \mathrm{~A}$ \\
\hline 3 & $20 \mathrm{~A}$ & $20 \mathrm{~A}$ \\
\hline
\end{tabular}

Dari hasil pengujian didapatkan kesimpulan bahwa modul sensor arus berfungsi dengan baik. Hal ini dibuktikan dengan 3 kali percobaan yang menunjukkan bahwa modul tersebut dalam keadaan baik.

\section{Modul Sensor Tegangan}

Pada rancangan ini penulis menggunakan sensortegangan sebagai sensor yang dapat membaca tegangan pada lampu prototype tersebut laludiproses oleh arduino nano dan dikirm ke LCD character $2 \times 16$ untuk ditampilkan. Sensor tegangan umumnya merupakan rangkaian pembagi tegangan atau pembagi tegangan konvensional. Pada pengujian modul ini dilakukan untuk memastikan modul berfungsi agar dapat ditampilan di modul LCD character $2 \times 16$ sudah bekerja dengan baik.

Tabel 8. Hasil Pengujian Modul Sensor Tegangan

\begin{tabular}{|c|c|c|}
\hline Uji ke- & $\begin{array}{c}\text { Input } \\
\text { Tegangan }\end{array}$ & $\begin{array}{c}\text { Output } \\
\text { Tegangan }\end{array}$ \\
\hline 1 & $12 \mathrm{~A}$ & $12.23 \mathrm{VDC}$ \\
\hline 2 & $12 \mathrm{~A}$ & $12.22 \mathrm{VDC}$ \\
\hline 3 & $12 \mathrm{~A}$ & $12.22 \mathrm{VDC}$ \\
\hline
\end{tabular}

Dari hasil pengujian didapatkan kesimpulan bahwa modul sensor tegangan berfungsi dengan baik. Hal ini dibuktikan dengan 3 kali percobaan yang menunjukkan bahwa modul tersebut dalam keadaan baik.

\section{Perangkat lunak (Software)}

Pada rangkaian alat ini, perangkat lunak (software) yang digunakan adalah Arduino Integrated Development Environment (IDE). Hasil pengujian pada pemograman mikrokontroler dengan Arduino IDE bisa dilihat pada tabel berikut:

Tabel 9. Hasil Pengujian Pemograman Pada Arduino IDE

\begin{tabular}{|c|l|c|}
\hline Uji ke- & Program & Status Verify \\
\hline 1 & $\begin{array}{l}\text { Modul Console pada } \\
\text { Arduino Nano 328 }\end{array}$ & DONE \\
\hline 2 & $\begin{array}{l}\text { Modul Client pada } \\
\text { Arduino Nano 328 }\end{array}$ & DONE \\
\hline 3 & $\begin{array}{l}\text { Modul LCD character } \\
2 \times 16 \text { pada } \\
\text { Arduino Nano 328 }\end{array}$ & DONE \\
\hline
\end{tabular}

\section{Pengujian}

\section{Deskripsi Pengujian}

Setelah melakukan perancangan langkah berikutnya menguji serta menganalisa rancangak pengoperasian jarak jauh yang telah dibuat. Pengujian ini bertujuan apakah rancangan sudah sesuai dengan pengoperasian yang diinginkan atau belum serta mengetahui apa saja kekurangan yang harus diperbaiki. 
Untuk melakukan pengujian tersebut diperlukan beberapa alat bantu diantaranya:
a. Google Maps
b. Handphone untuk merekam pengujian
c. Kabel NYMHYO
d. Tang
e. Multitester

\section{Prosedur Pengujian}

Proses pengujian dilakukan setelah semua rangkaian telah siap. Dan langkah pengujian sebagai berikut

- Menyambungkan sumber tegangan 12 VDC

- dari aki ke modul client dengan cara menjumper rangkaian

- pengoperasian manual dengan kabel NYMHYO

- dan pastikan penyambungan tidak terbalik, tetapi dalam hal ini dilakukan pada catu daya replika prototype tersebut

\section{Interpretasi Hasil Pengujian}

Dari hasil uji coba rancang bangun kontrol dan monitoring pada emergency solar runway edge light, dapat bekerja dengan baik secara keseluruhan tetapi dikarenakan keadaan masih pandemi maka diuji coba menggunakan sejenis lampu prototype tersebut. Dan pada rancangan ini dapat mengoperasikan lebih dari satu lampu, dengan syarat terdapat modul client disetiap lampu dengan cara membedakan alamat disetiap kedua modul tersebut.

Tetapi pada rancangan ini masih terdapat kekurangan padajarak yang bisa ditempuh yaitu $\pm 2 \mathrm{KM}$, ketika dilakukan pengujian hanya dapat mengoperasikan dengan jarak $1200 \mathrm{M}$ seperti pada hasil pengujian yang dapat dilihat pada table uji coba keempat. Lalu ketika dilakukan uji coba kelima dengan jarak \pm 1300 lampu tidak dapat dioperasikan. Hal ini diharapkan kedepannya ada pengembangan lebih lanjut, sehingga bisa diaplikasikan pada dunia penerbangan salah satunya wilayah sisi udara

\section{KESIMPULAN}

1. Sistem monitoring yang digunakan pada rancangan ini untuk pengoperasian jarak jauh memudahkan teknisi atau operator dalam mengoperasikan lampu.

2. Dengan melihat status lampu ketika nyala dan tampilan data sensor arus dan tegangan. Hasil tampilan di layer LCD character $2 \times 16$
3. Sebagai referensi pengembangan pengoperasian lebih dari satu lampu.

\section{Saran}

Berdasarkan kesimpulan yang telah diuraikan, rancang bangun kontrol dan monitoring prototype emergency solar runway edge light ini masih memiliki kekurangan. Maka penulis memiliki beberapa saran terhadap rancangan yang dibuat, sebagai berikut

1. Di karenakan dengan jarak $\pm 2 \mathrm{KM}$

dalam status pengoperasiannya masih kurang ketika diterapkan di runway dari unit $\mathrm{PH}$,penulis memilik saran dengan mengatasi kendala dengan cara mengirim data secara estafet dari satu lampu ke lampu lain contohnya lampu 60 ke 59 dengan data yang sudah di programkan di

Arduino IDE sehigga untuk pengoperasiannya tetap satu modul console.

2. Menggunakan LCD dengan ukuran yang lebih besar agar dapat memuat data - data banyak yang dibutuhkan digunakan pada pengoperasian lebih dari satu lampu.

3. Pendalaman lebih lanjut agar pengoperasian dengan kendali komunikasi jarak jauh dengan dua arah mencapai target yang sesuai untuk pengoperasiannya yaitu \pm $2 \mathrm{KM}$.

4. Mencari refrensi refrensi tentang pengoperasian jarak jauh dengan rancangan dua arah agar dapat diaplikasikan di dunia penerbangan

\section{Daftar Pustaka}

B. W. Utomo, 2010 "Pintu Otomatis Menggunakan Remote Control “ Diajukan Untuk Memenuhi Salah Satu Syarat Mencapai Gelar Ahli Madya PrograM Diploma III Ilmu Komputer.

International Civil Aviation Organization (ICAO) 2016, Aerodromes Design \& Operations - Annex 14, Vol. I, No. July. 2016.

M. Intensity, 2016 "Sp-401 Solar Runway Edge Light," Pp. 1- 2, 
U. J. Shobrina, R. Primananda, And R. Maulana, 2018 "Analisis Kinerja Pengiriman Data Modul Transceiver NRF24101 , Xbee Dan Wifi ESP8266 Pada Wireless Sensor Network," J. Pengemb. Teknol. Inf. Dan Ilmu Komput., Vol. 2, No. 4, Pp. 1510-1517, 2018.

Y. B. Yonanda, "Monitoring Arus Beban Yang Tersalurkan Pada Gardu Induk PLTU Gresik Dengan Android Menggunakan Bluetooth HC-O5 Berbasis Mikrokontroler ARM," Gresik, Pp. 6-16, 2017

N. Jenggawah, S. Pada, K. Berpikir, K. Dan, And M. Belajar, Digital Digital repository Repository Universitas Universitas Jember Jember Digital Jember Digital Repository Repository Universitas Universitas Jember. 